HORN, M.B. et al. Qualidade de silagens de milho para gado leiteiro produzidas na Região Sul do Brasil quanto às micotoxinas. PUBVET, Londrina, V. 8, N. 2, Ed. 251, Art. 1664, Janeiro, 2014.

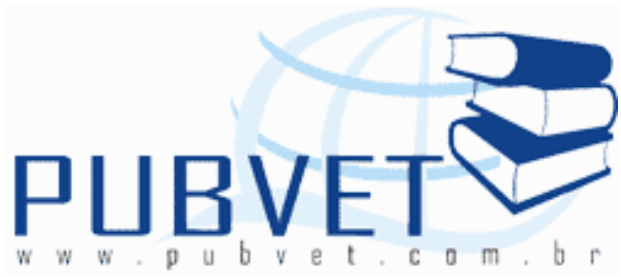

PUBVET, Publicações em Medicina Veterinária e Zootecnia.

\title{
Qualidade de silagens de milho para gado leiteiro produzidas na Região Sul do Brasil quanto às micotoxinas
}

\author{
Marcelina Bottonni Horn ${ }^{1,2}$, Rafael Luchtenberg ${ }^{1,2}$, Maria Amélia Assunção², \\ Silvio Alexandre Santos ${ }^{2}$, Vildes Maria Scussel ${ }^{1}$
}

1 Laboratório de Micotoxicologia e outros Contaminantes Alimentares LABMICO. Departamento de Ciência e Tecnologia dos Alimentos. Centro de Ciências Agrárias, Universidade Federal de Santa Catarina, Rod Admar Gonzaga, 1346, Itacorubi, Florianópolis, Santa Catarina;

${ }^{2}$ Nutrifarma, Taio, Santa Catarina, Brasil e-mail: marcelinabh@oi.com.br

\section{Resumo}

A qualidade de silagens de milho (Zea mays L.), quanto a presença de micotoxinas de campo (fumonisinas - FBs e zearalenona - ZON) e de armazenagem (aflatoxinas - AFLs), fornecidas ao gado leiteiro da região Sul do Brasil foi avaliada no período de janeiro de 2010 à dezembro de 2012. As análises, em um total de 1006, 1077 e 1080 para FBs, ZON e AFLs foram realizadas pelo método imunoenzimático (ELISA) com LOQ de 500, 25 e 5 $\mu \mathrm{g} / \mathrm{kg}$, respectivamente. Dos dados obtidos foi possível observar que houve contaminação em diferentes amostras e que os níveis encontrados variaram tanto quanto a toxina avaliada quanto ao período do ano contudo, pouco foi sua variação nos estados que compreendem a região de clima temperado, em estudo. A toxina produzida por Fusarium graminearum, ZON, esteve presente 
HORN, M.B. et al. Qualidade de silagens de milho para gado leiteiro produzidas na Região Sul do Brasil quanto às micotoxinas. PUBVET, Londrina, V. 8, N. 2, Ed. 251, Art. 1664, Janeiro, 2014.

com ampla variação entre os níveis de 28,2 e $1538 \mu \mathrm{g} / \mathrm{kg}$ com desvio padrão DP \& desvio padrão relativo - DPR\% de 131,3 \& 65,4\%), independente da origem da amostra ou período de avaliação. Dessas amostras, 75,5 \% estava acima do limite máximo tolerável (LMT) estabelecido no Uruguai $(200 \mu \mathrm{g} / \mathrm{kg}$ ) para cereais destinados a alimentação animal (embora não cite especificamente para silagem). Não há limite estabelecido no Brasil para ZON em ração. As FBs foram as toxinas que apresentaram menor porcentagem de amostras contaminadas (11,4 a 34,4\%) entre os anos de estudo, sendo em 2011 o que apresentou níveis mais elevados. Contudo, todos abaixo do LMT dos Estados Unidos ( $30.000 \mu \mathrm{g} / \mathrm{kg}$ ) e 7,3\% acima do limite estabelecido pela Suiça $(1.000 \mu \mathrm{g} / \mathrm{kg})$. Não existem limites estabelecido para FBs no Brasil para alimentação animal. Quanto as AFLs, a porcentagem de amostras contaminadas com níveis superiores ao LMT brasileiro (Ministério da Agricultura - $50 \mu \mathrm{g} / \mathrm{kg}$ ) foi de somente $11,6 \%$ (125) do total de 1080 silagens analisadas. Os níveis variaram ente as amostras positivas, com 9,7\% (46-97 $\mu \mathrm{g} / \mathrm{kg}), 11,3 \%(31-125,8 \mu \mathrm{g} / \mathrm{kg})$ e $14,5 \%(48-105,4 \mu \mathrm{g} / \mathrm{kg})$ para os estados de $\mathrm{PR}$, RS e SC, respectivamente. Embora os níveis detectados para FBs tenham sido baixos, os de AFLs e ZON foram mais elevados, inclusive algumas amostras acima do LMT de diferentes paises. Portanto, existe a necessidade de adequação das práticas agricolas na produção da silagem para o gado leiteiro em suas diversas etapas (colheita / moagem da planta / fermentação / compactação \& no tipo / tamanho / fechamento dos silos) bem como seu constante monitoramento, para evitar ou minimizar os eventuais danos econômicos. Esse é o primeiro trabalho relatando toxinas em silagem de clima temperado.

Palavras-chave: silagem, milho, aflatoxinas, fumonisinas, zearalenona, gado, região sul, micotoxinas. 
HORN, M.B. et al. Qualidade de silagens de milho para gado leiteiro produzidas na Região Sul do Brasil quanto às micotoxinas. PUBVET, Londrina, V. 8, N. 2, Ed. 251, Art. 1664, Janeiro, 2014.

\section{Corn silage quality for dairy cattle produced in southern Brazil regarding mycotoxins}

\section{Abstract}

Silage corn (Zea mays L.) quality was evaluated from January 2010 to December 2012 for the presence of field (fumonisins-FBs and zearalenoneZON) and storage (aflatoxins-AFLs) mycotoxins, supplied to dairy cattle in the Southern Brazil. A total analysis of 1,006, 1,077 and 1,080 for FBs, ZON and AFLs were performed by the immunoenzymatic (ELISA) methodology with LOQ of 500,25 and $5 \mu \mathrm{g} / \mathrm{kg}$, respectively. From the data obtained it was observed that there was contamination in different samples, the levels varied and so the toxin evaluated throughout the period of the year. Although, not much difference among the states that comprise the region (temperate climate) under study, was detected. The toxin produced by Fusarium graminearum, ZON, was present ranging from 28.2 to $1538 \mu \mathrm{g} / \mathrm{kg}$ indicating a large variability between levels (standard deviation-SD \& relative standard deviation-RSD\% of $131 \& 65.4 \%$ ) regardless of the origin of the sample or trial period. There is no ZON limit established in Brazil for feed. Out of these samples, $75.5 \%$ were above the maximum tolerable (LMT) established in Uruguay $(200 \mu \mathrm{g} / \mathrm{kg})$ for cereals for animal feed, although the country does not specify for silage. The FBs were the toxins that had the lowest percentage of contaminated samples (11.4 to $34.4 \%$ ) between the years of study, with the year 2011 presenting the highest levels yet, all below LMT U.S.A. (30,000 $\mathrm{\mu g} /$ $\mathrm{kg})$ and $7.3 \%$ above the limit set by Switzerland $(1,000 \mu \mathrm{g} / \mathrm{kg})$. There are no limits set for FBs in Brazil feed. Regarding AFLs, the percentage of samples contaminated with levels higher than the Brazilian LMT (Ministry of Agriculture - $50 \mu \mathrm{g} / \mathrm{kg}$ ) was $11.6 \%$ (125) of the total of 1080 tested silages. The levels varied among the positives samples with 9.7\% (46-97), 11.3\% (31-125.8) and $14.5 \%$ (48-105.4) for the states of PR, RS and SC, respectively. Although the levels detected for FBs were low, AFLs and ZON were higher, being some above the LMT of different countries. Therefore there is the need for 
HORN, M.B. et al. Qualidade de silagens de milho para gado leiteiro produzidas na Região Sul do Brasil quanto às micotoxinas. PUBVET, Londrina, V. 8, N. 2, Ed. 251, Art. 1664, Janeiro, 2014.

agricultural practices adequacy in the production of silage for dairy cattle through several stages (harvesting / milling plant / fermentation / compression \& silo type / size \& closure) as well as its constant monitoring in order to avoid or minimize any economic losses. This is the first work reporting toxins of temperate climate in silage.

Keywords: silage, corn, aflatoxins, fumonisins, zearalenone, cattle, southern, mycotoxins.

\section{INTRODUÇÃO}

A utilização de silagem de milho (planta integral - incluindo espigas triturada e fermentada) na alimentação do gado leiteiro é uma prática comum no Brasil. Constitui de 50 a $75 \%$ da dieta desses animais, principalmente nos períodos de entre safra das pastagens onde há redução do volumoso disponível (DRIEHUIS et al., 2008). Condições no campo e no armazenamento, tais como variações na temperature durante plantio, tempos chuvosos - que leva à alterações na umidade relativa, bem como condensações (formação de microclimas) nos silos, além de infestação por insetos, podem levar à contaminação indesejável por fungos e a produção de micotoxinas (KELLER et al., 2013, SCUSSEL, 1998; HORN et al., 2011), as quais são compostos sintetizados pelo metabolismo secundário de diferentes gêneros fúngicos.

Em comparação com outros animais, os ruminantes são mais resistentes para muitas micotoxinas, possivelmente devido à biotransformação pelos microorganismos do rúmen (EFSA, 2005). No entanto, quando ingeridas pelo gado leiteiro podem provocar sintomas, como a diminuição da ingestão de alimentos, do peso e na produção de leite (DRIEHUIS et al., 2008). Dano no fígado também tem sido citado (QUEIROZ et.al, 2012).

O grupo de toxinas mais estudado e já reconhecido como afetando a saúde desses animais é o de armazenagem (aflatoxinas - AFLs). Embora também tenham sido relatados efeitos nocivos na performance de outros animais com possibilidade de redução na produção de leite quando na 
HORN, M.B. et al. Qualidade de silagens de milho para gado leiteiro produzidas na Região Sul do Brasil quanto às micotoxinas. PUBVET, Londrina, V. 8, N. 2, Ed. 251, Art. 1664, Janeiro, 2014.

presença de outros grupos de toxinas tais como as de campo (fumonisinas FBs e zearalenona - ZON) (NONES e SCUSSEL, 2013; SCUSSEL, 2004). Contudo poucos são os estudos relatados na literatura em ruminantes.

Ruangwises \& Ruangwises (2010) citam que a presença de AFLs na alimentação do gado leiteiro gera uma preocupação de ordem pública, já que a aflatoxina $B_{1}\left(A F B_{1}\right)$ pode ser biotransformada no organismo do animal em aflatoxina $M_{1}\left(A F M_{1}\right)$, contaminando o leite a qual é tão tóxica quanto a percussora. A transferência de AFLs da ração para o leite é influenciada por vários fatores nutricionais e fisiológicos, incluindo regimes alimentares, a taxa de ingestão e digestão, saúde do animal, capacidade de biotransformação hepática e produção de leite (DUARTE et al., 2013; TONON et al., 2012).

Quanto as toxinas de campo, a ZON possui propriedades estrogênicas, ocasionando diminuição da fertilidade, taxa de ovulação e produção de leite, vaginite, aumento uterino e repetição de cio para vários animais incluindo em menor grau o gado (SMITH et al., 1990; SASSAHARA et al., 2003; BORUTOVA et al., 2012; NONES e SCUSSEL, 2013). Em um estudo publicado por Weaver et al (1986) as taxas de concepção de novilhas leiteira diminuíram de 87 para $62 \%$ quando foi administrado diariamente $250.000 \mu \mathrm{g}$ de ZON (através de uma cápsula de gelatina). Já as FBs quando presentes nas dietas de diferentes espécies animais provocam dano morfológico, celular e bioquímico (D'MELLO et al., 1999; SCAFF e SCUSSEL, 2004). Essas toxinas são pouco metabolizadas pela microflora do rumen (CALONI et al., 2000) e microssomas do fígado (SPOTTI et al., 2001), no entanto podem ser observadas alterações renais e hepáticas (MATHUR et al, 2001).

A ocorrência destas micotoxinas pode ser devido a diversidade de clima do Brasil variando de tropical, semitropical a temperado (clima da região em estudo) e da grande variabilidade sazonal destas condições - alterando temperatura em períodos de chuva que influenciam as práticas agricolas e a qualidade dos alimentos (SCUSSEL, 2004; SIMGE, 2011).

Os limites máximos toleráveis (LMT) estabelecidos para micotoxinas em alimentação animal variam entre países e grupo de toxinas avaliadas, bem 
HORN, M.B. et al. Qualidade de silagens de milho para gado leiteiro produzidas na Região Sul do Brasil quanto às micotoxinas. PUBVET, Londrina, V. 8, N. 2, Ed. 251, Art. 1664, Janeiro, 2014.

como o tipo de alimento, espécie e características dos animais. Atualmente, para alimentação animal, poucos paises tem estes valores estabelecidos. No Brasil, a legislação estabelece LMT de $50 \mu \mathrm{g} / \mathrm{kg}$ de AFLs para alimentação animal (BRASIL, 1988). Contudo para a silagem utilizada na alimentação de bovinos e administrada juntamente com ração e pastagem verde, não existe legislação específica. Já para o Mercosul o LMT foi estabelecido somente para AFLs $(20 \mu \mathrm{g} / \mathrm{kg})$ em ração animal e não especifica para gado leiteiro (MERCOSUL, 2002). Da mesma forma, para FBs, internacionalmente os EUA toleram $30.000 \mu \mathrm{g} / \mathrm{kg}$ para FBs para alimentação bovina de leite e $20 \mu \mathrm{g} / \mathrm{kg}$ para AFLs. Já a União Européia estabelece limites para AFLs em alimentos para bovinos de 20, 10 e $5 \mathrm{\mu g} / \mathrm{kg}$ para matérias-primas \& alimentos compostos; alimentos complementares e animais jovens \& vacas em lactação, respectivamente $(C E, 2002)$. A Suíça estabelece como $1.000 \mu \mathrm{g} / \mathrm{kg}$ de FBs para milho. Para a ZON, no Uruguai são permitidos limites máximos de 200 $\mu \mathrm{g} / \mathrm{Kg}$ para milho e cevada em alimentação animal; na Áustria, os limites permitidos para rações de suínos matrizes são $50 \mu \mathrm{g} / \mathrm{Kg}$; na França, $50 \mu \mathrm{g} / \mathrm{Kg}$ para cereais em geral e $200 \mu \mathrm{g} / \mathrm{Kg}$ para óleos vegetais; na Itália, $100 \mu \mathrm{g} / \mathrm{Kg}$ para cereais $(F A O, 2004)$.

O conhecimento a respeito dos níveis máximos de micotoxinas aceitáveis na silagem ainda não é bem estabelecido, bem como a relação entre manejo do painel do silo e incidência desses compostos nas silagens. Extra oficialmente, no Brasil, em estudos realizados pela Universidade Federal do Paraná (UFPR) através do Centro de Pesquisas em Forragicultura - CPFOR (UFPR, 2011) foram estabelecidos LMTs para silagens com faixas entre (a) aceitável e (b) crítico sendo para AFB ${ }_{1}$, ZON e FBs de: (a): <1000, <285 e $<19 \mu \mathrm{g} / \mathrm{kg}$ e (b): $>1000,>286$ e $>20 \mu \mathrm{g} / \mathrm{kg}$, respectivamente (UFPR, 2011).

Considerando a falta de dados quanto a toxinas de campo - típicas de regiões de clima temperado, bem como a necessidade de conhecer as reais condições das silagens fornecidas aos animais na região Sul do Brasil, o objetivo deste estudo foi verificar a qualidade das silagens de milho, quanto a possível contaminação por toxinas de campo (ZON e FBs) e de armazenagem 
HORN, M.B. et al. Qualidade de silagens de milho para gado leiteiro produzidas na Região Sul do Brasil quanto às micotoxinas. PUBVET, Londrina, V. 8, N. 2, Ed. 251, Art. 1664, Janeiro, 2014.

(AFLs) fornecidas ao gado leiteiro de regiões produtoras de milho dos estados da Região Sul do Brasil. Esse é o primeiro trabalho relatando toxinas em silagem de clima temperado.

\section{MATERIAL E MÉTODOS}

\subsection{MATERIAL}

a) Amostras: silagens de milho (1081) provenientes de propriedades rurais da região sul do Brasil (estados: Paraná - PR, Rio Grande do Sul - RS, Santa Catarina - SC), mais especificamente de suas respectivas regiões de maior produção de milho (oeste/sudoeste - 476, noroeste - 275 e oeste - 330) entre o período de 2010 a 2012. A Figura 1 apresenta as regiões por estado da região Sul onde estão localizadas as propriedades do estudo e a Tabela 1 detalhes do número de amostras, bem como o percentual que elas representam por ano e por toxina avaliada.

b) Testes de micotoxinas por imunoensaio: foram utilizados 3 conjuntos diferentes de análise, baseados em ensaios imunoenzimáticos (ELISA) quantitativos para determinação de, FBs, ZON e AFLs, art. 8835/8836, 8110 e 8030, respectivamente, modelo Veratox (Neogen). Os conjuntos eram compostos por (b.1) padrões de $\mathrm{FBs}\left[\mathrm{FB}_{1}+\mathrm{FB}_{2}\right]$, ZON e AFLs totais $\left[\mathrm{AFB}_{1}+\mathrm{AFB}_{2}+\mathrm{AFG}{ }_{1}+\mathrm{AFG} \mathrm{F}_{2}\right]$ nas concentrações de 500/1000/3000/6000, $25 / 75 / 150 / 500$ e $5 / 15 / 50 \mu \mathrm{g} / \mathrm{Kg}$, respectivamente em metanol $70 \%$ mantendo um branco como controle (somente solvente - zero $\mu \mathrm{g} / \mathrm{Kg}$ ) para cada curva. Além de (b.2) substrato (marcador de cor K-Blue) e (b.3) conjugado (toxinas enzimo-marcadas). 
HORN, M.B. et al. Qualidade de silagens de milho para gado leiteiro produzidas na Região Sul do Brasil quanto às micotoxinas. PUBVET, Londrina, V. 8, N. 2, Ed. 251, Art. 1664, Janeiro, 2014.

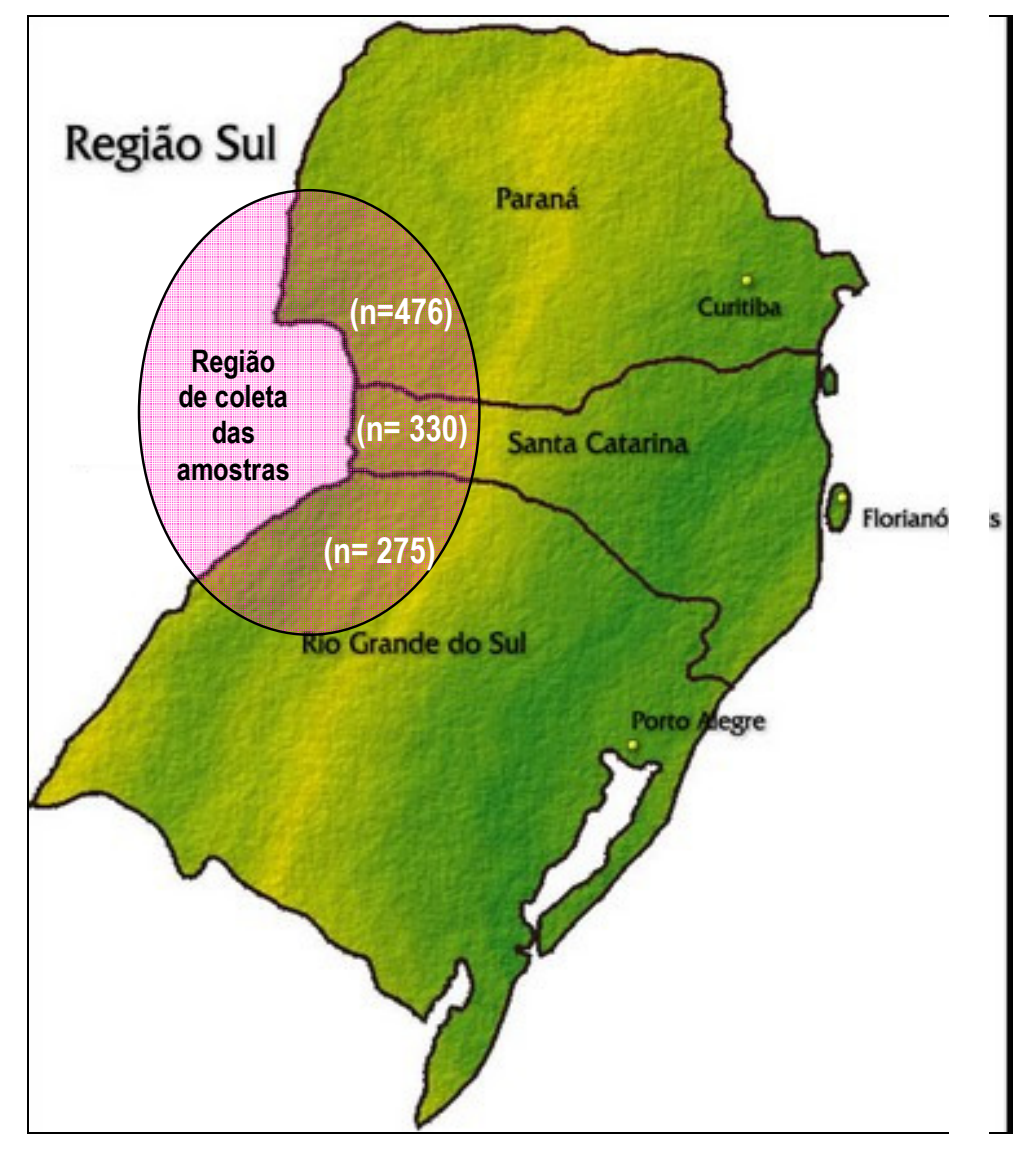

Figura 1. Região Sul do Brasil com as regiões de coleta e número de amostras de silagem de milho (Zea mays L.) ( www.portalbrasil.net - modificado, 2013).

c) Equipamentos: estufa de secagem (Quimis), termômetro para estufa (faixa -10 a $160^{\circ} \mathrm{C}$ ), balança semi-analítica (Ohaus), moinho de ultra centrifugação (peneira de $1 \mathrm{~mm}$ ), modelo ZM200 (Retsch) e leitora de microplacas modelo Stat-Fax 4700 (Neogen).

d) Outros materiais: metanol p.a. (FMaia), micropipetas monocanal e multicanal (100 $\mu \mathrm{L}$ e $100-1000 \mu \mathrm{L}$ ) e respectivas ponteiras (Brand); frascos para coleta de polipropileno (80 $\mathrm{mL}$ ) com tampa (JProlab); luvas de látex descartáveis (Supermax); bandejas de alumínio $(150 \times 200 \mathrm{~mm})$; conchas metálicas e pás para coleta e saco de polietileno (tamanho $17 \times 34 \mathrm{~cm}$ ). 
HORN, M.B. et al. Qualidade de silagens de milho para gado leiteiro produzidas na Região Sul do Brasil quanto às micotoxinas. PUBVET, Londrina, V. 8, N. 2, Ed. 251, Art. 1664, Janeiro, 2014.

Tabela 1. Número de amostras de silagem de milho (Zea mays $L$ ) produzidas na região sul do Brasil avaliadas para micotoxinas - janeiro/2010 a dezembro/2012

\begin{tabular}{|c|c|c|c|c|c|}
\hline \multirow{2}{*}{ Micotoxina } & \multirow{2}{*}{ Ano } & \multicolumn{4}{|c|}{ No de amostras avaliadas $(\%) *$} \\
\hline & & $\mathbf{P R}^{\mathbf{a}}$ & $\mathbf{R S}^{\mathbf{b}}$ & $\mathbf{S C}^{\mathbf{C}}$ & Região Sul \\
\hline \multicolumn{6}{|c|}{ TOXINAS DE CAMPO } \\
\hline \multicolumn{6}{|l|}{ Fumonisinas } \\
\hline 2010 & & $88(41)$ & $65(31)$ & $59(28)$ & $212(100)$ \\
\hline 2011 & & $131(41)$ & $96(31)$ & $90(28)$ & $317(100)$ \\
\hline \multirow[t]{2}{*}{2012} & & $257(54)$ & $111(23)$ & $109(23)$ & $477(100)$ \\
\hline & Total: & $476(47)$ & $272(28)$ & $258(25)$ & $1006(100)$ \\
\hline \multicolumn{6}{|l|}{ Zearalenona } \\
\hline 2010 & & $88(41)$ & $65(31)$ & $59(28)$ & $212(100)$ \\
\hline 2011 & & $127(39)$ & $96(29)$ & $104(32)$ & $327(100)$ \\
\hline \multirow[t]{2}{*}{2012} & & $257(48)$ & $114(21)$ & $167(31)$ & $538(100)$ \\
\hline & Total: & $472(43)$ & 275(26) & $330(31)$ & $1077(100)$ \\
\hline
\end{tabular}

TOXINAS DE ARMAZENAGEM

Aflatoxinas

\begin{tabular}{|c|c|c|c|c|}
\hline 2010 & $88(41)$ & $65(31)$ & $59(28)$ & $212(100)$ \\
\hline 2011 & $131(40)$ & 96 (29) & $104(31)$ & $331(100)$ \\
\hline 12 & $256(48)$ & $114(21)$ & $167(31)$ & 537 (100) \\
\hline & $475(44)$ & $275(26)$ & $330(30)$ & $1080(100)$ \\
\hline
\end{tabular}

*Número total de amostras coletadas $=1081$ (sendo que nem todas as amostras foram analisadas para as 3 toxinas conjuntamente i.e, total de 1006, 1077 e 1080 amostras para FBs, ZON e AFLs, respectivamente). ${ }^{\text {a Paraná }}{ }^{\mathrm{b}}$ Rio Grande do Sul ${ }^{\mathrm{c}}$ Santa Catarina

e) Legislações: (e.1) Brasil - Ministério da Agricultura e Abastecimento Portaria MA/SNAD/SFA n07 (1988); (e.2) Estados Unidos - Food and Drugs Administrastion - Animal veterinary products, food and feed contaminants, 9/11/1988, Section 1 (1988); (e.3) União Européia - Directiva 2002/32 relativa às substâncias indesejáveis nos alimentos para animais (2002, alterada em 06.09.2012); (e.4) Mercosul - GMC-Grupo Mercado ComumResolução no 25/02 (2002); (e.5) Outros países: Suiça, Uruguai, França, Itália compilado da FAO Worldwide Regulations for Mycotoxins (2004). 
HORN, M.B. et al. Qualidade de silagens de milho para gado leiteiro produzidas na Região Sul do Brasil quanto às micotoxinas. PUBVET, Londrina, V. 8, N. 2, Ed. 251, Art. 1664, Janeiro, 2014.

\subsection{MÉTODOS}

a) Coleta das amostras: as amostras foram coletadas no período de janeiro de 2010 a dezembro de 2012 de silos (do Tipo trincheira e de superfície) localizados em propriedades do oeste/sudoeste, noroeste e oeste dos 3 estados, respectivamente (Seção 2.1.a). Foram coletadas de diferentes pontos e profundidades da massa da silagem, com auxílio de conchas/pás ou manualmente (com uso de luvas descartáveis). A amostra coletada (cerca de 5 $\mathrm{kg}$ ) foi homogeneizada manualmente e submetida a quarteamento em uma superfície limpa até redução de peso para $1 \mathrm{~kg}$, a qual foi acondicionada em saco de polietileno (devidamente identificado) e enviado para análise laboratorial. A média de conteúdo de umidade foi de 67,65\% (min. 63,92\% e máx. $82,14 \%$ ) entre as silagens analisadas.

b) Preparo das amostras: cada amostra (1 kg) foi seca em estufa a temperatura de $60{ }^{\circ} \mathrm{C} \pm 5^{\circ} \mathrm{C}$ conforme metodologia proposta por Silva (1998) até umidade final de aproximadamente $2 \%$, triturada em moinho de ultra centrifugação (peneira de $1 \mathrm{~mm}$ ) e porções de $5 \mathrm{~g}$ foram separadas para análise de FBs, ZON e AFLs.

c) Análises de micotoxinas: a metodologia utilizada foi a desenvolvida por Neogen (NEOGEN, 2013.a,b,c). Foram utilizadas $5 \mathrm{~g}$ (Item 2.2.a) de cada amostras preparadas acima, as quais foram extraídas as toxinas/método com mistura $(25 \mathrm{~mL})$ de metanol e água $(70: 30 \mathrm{v} / \mathrm{v})$ por $3 \mathrm{~min}$. Essa mistura foi mantida em repouso por ca. 2 min, filtrada e utilizada para o ensaio imunoenzimático. Foi utilizado o conjunto de Elisa Veratox respectivo para cada toxina em análise (Seção 2.1.b) acrescentando volumes $(\mathrm{mL})$ dos padrões de diferentes concentrações, o reagente de cor (substrato) e os conjugados (toxinas enzimo-marcadas) ocorrendo então desenvolvimento de cor pela reação antígeno anticorpo. A cor formada era inversamente proporcional à concentração da micotoxina. Os padrões em diferentes 
HORN, M.B. et al. Qualidade de silagens de milho para gado leiteiro produzidas na Região Sul do Brasil quanto às micotoxinas. PUBVET, Londrina, V. 8, N. 2, Ed. 251, Art. 1664, Janeiro, 2014.

concentrações foram utilizados para desenvolver a curva de calibração e a partir da qual, as concentrações das amostras foram calculadas automaticamente pela leitora ELISA (através de sua absorbância em $650 \mathrm{~nm}$ ). Os limites de deteç̧ão (LOD)/de quantificação (LOQ) do método utilizado por toxina foi de 200/500; $10 / 25$ e 1,4/5,0 $\mu \mathrm{g} / \mathrm{kg}$, para FBs, ZON e AFLs, respectivamente. Na Figura 2 encontramos as curvas de calibração para cada uma das toxinas analisadas, respectivamente. Nota: como a metodologia utilizada (a) apresenta informações de validação com LOD e LOQ e (b) considerando que para análises quantitativas é utilizado o dado mais consistente e reproductível (em 10 repetições) - definido como LOQ - foram considerados como resultados positivos de contaminação, aqueles que obtiveram concentrações $\geq$ LOQ (500/25/5 $\mu \mathrm{g} / \mathrm{kg}$ ) para FBs / ZON / AFLs, respectivamente.

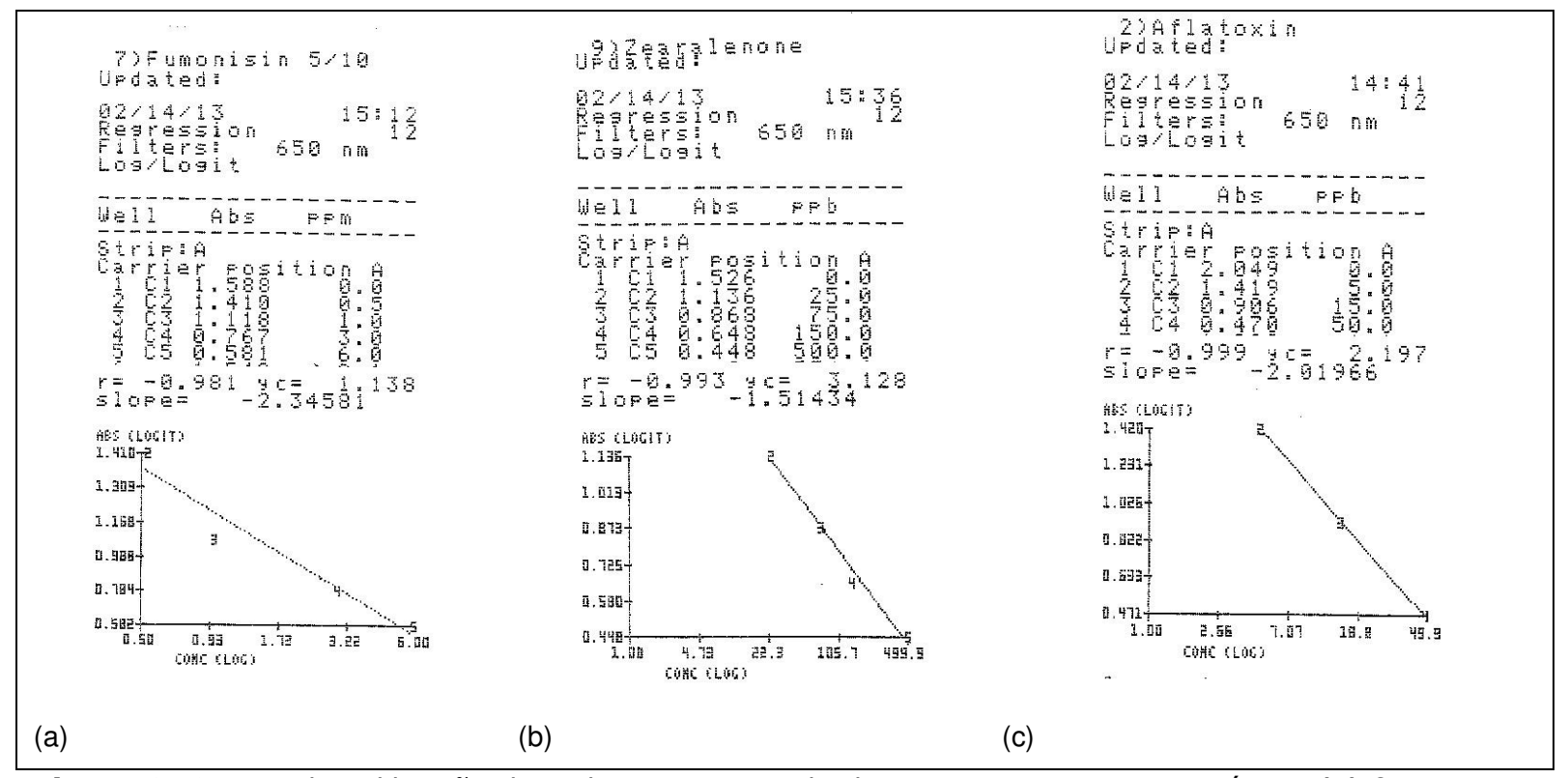

Figura 2. Curvas de calibração de cada micotoxina obtida por ensaio imunoenzimático: (a) fumonisinas, (b) zearalenona e (c) aflatoxinas [faixa de concentração de 500 a 6000, 25 a 500 e 5 a 50 mg/kg, respectivamente]. 
HORN, M.B. et al. Qualidade de silagens de milho para gado leiteiro produzidas na Região Sul do Brasil quanto às micotoxinas. PUBVET, Londrina, V. 8, N. 2, Ed. 251, Art. 1664, Janeiro, 2014.

d) Dados climatológicos: os dados de umidade relativa (UR\%), temperatura $\left({ }^{\circ} \mathrm{C}\right)$ e pluviométricos $(\mathrm{mm})$ foram obtidos através do Instituto Nacional de Meteorologia (INMET, 2013).

e) Conteúdo de umidade: realizado pelo método do AOAC (2005).

f) Estatística: foram utilizados parâmetros estatísticos incluídos no software Microsoft - Excel para desvio padrão (DP), desvio padrão relativo por cento (DPR\%), média e faixas (min.; máx.).

A Figura 3 apresenta o fluxograma do estudo da contaminação por FBs, ZON e AFLs em silagens de milho para bovinos provenientes da região sul do Brasil.

\section{RESULTADO E DISCUSSÃO}

A partir dos dados obtidos foi possível observar contaminação em algumas amostras de silagens de milho, bem como variações nos níveis dessa contaminação para as micotoxinas de campo (FBs e ZON) e de pós-colheita (AFLs) produzidas na Região Sul. A variabilidade nos valores detectados foi indicada pelos DP, DPR\% e respectivas faixas de contaminação (máximos e mínimos) para as toxinas avaliadas (Tabela 2). As Figuras 4-6 apresentam comparação dos dados obtidos para as três micotoxinas por estado e ano de coleta. 
HORN, M.B. et al. Qualidade de silagens de milho para gado leiteiro produzidas na Região Sul do Brasil quanto às micotoxinas. PUBVET, Londrina, V. 8, N. 2, Ed. 251, Art. 1664, Janeiro, 2014.

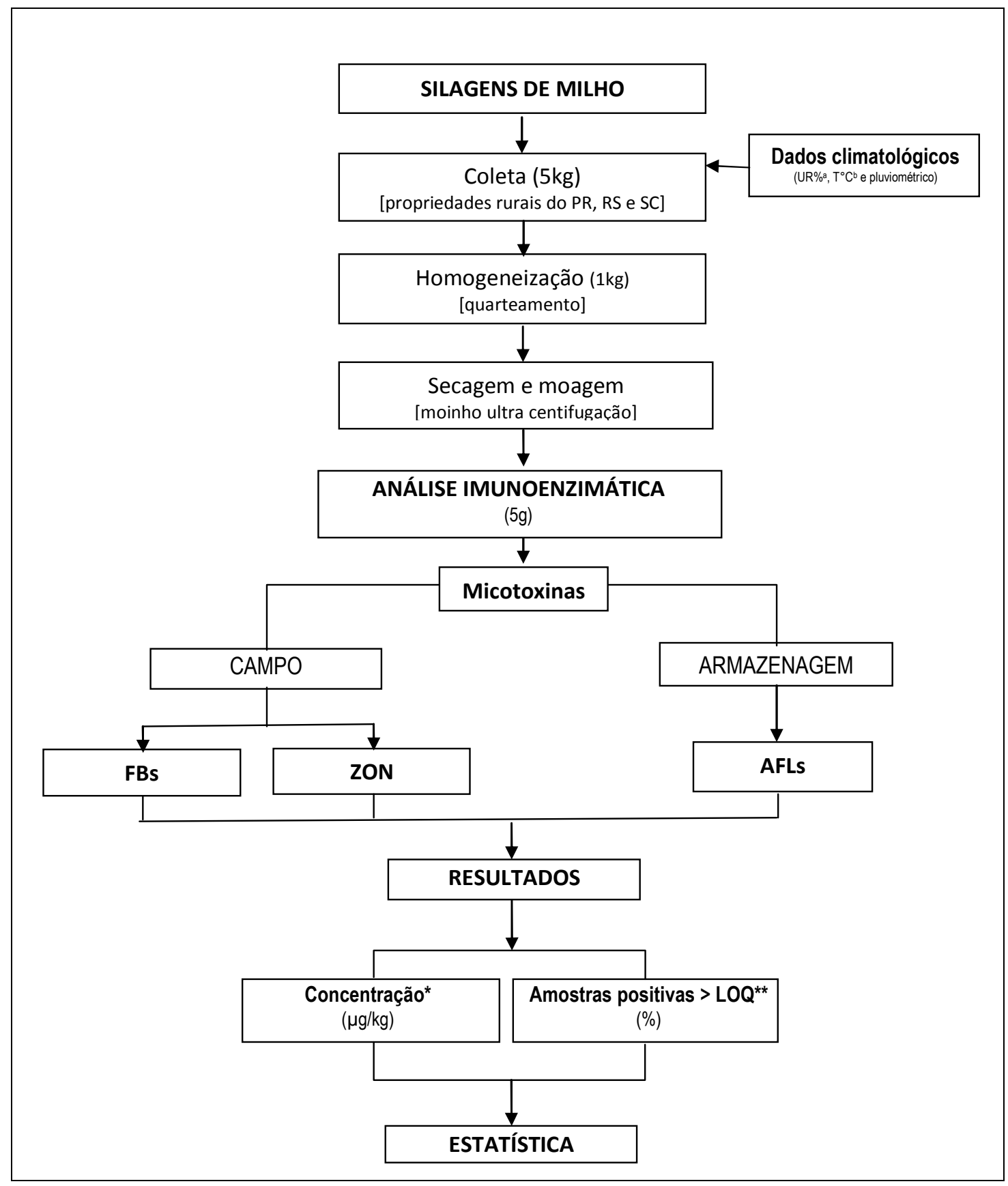

Figura 3. Fluxograma do estudo da contaminação por toxinas de (a) campo (FBs - fumonisinas, ZON zearalenona) e (b) toxinas pós-colheita / armazenagem (AFLs - aflatoxinas ) em silagens de milho para bovinos provenientes da região sul do Brasil (PR - Paraná, RS - Rio Grande do Sul e SC - Santa Catarina) [ ${ }^{a}$ umidade relativa, ${ }^{b}$ temperatura, $*$ concentração de toxinas $\geq * *$ limite de quantificação (LOQ): 500, 25 e $5 \mu \mathrm{g} / \mathrm{kg}$, respectivamente] 
HORN, M.B. et al. Qualidade de silagens de milho para gado leiteiro produzidas na Região Sul do Brasil quanto às micotoxinas. PUBVET, Londrina, V. 8, N. 2, Ed. 251, Art. 1664, Janeiro, 2014.

\section{a) Níveis de Micotoxinas e Porcentagens de Amostras Contaminadas}

(a.1) Toxinas de campo: considerando as toxinas de Fusarium que se desenvolvem durante o cultivo do milho ainda no campo, cujas plantas são utilizadas integralmente para a produção da silagem, tanto as FBs quanto ZON produzidas por Fusarium verticilioides e F. graminearum, respectivamente foram detectadas em níveis e números diferentes dependendo do ano e estado da Região Sul (Tabela 2).

As FBs foram detectadas em uma porcentagem reduzida de amostras, ou seja em somente 7,3\% (74), com valores superiores a $1.000 \mu \mathrm{g} / \mathrm{kg}$ (LMT Suiça) no período da pesquisa para os três estados, sendo 2012, o ano que apresentou o menor número de amostras positivas (12,8 e 18,9\%) para os estados de SC e RS (Figura 5). Considerando os níveis de contaminação por FBs, esses variaram de $600-1.800,500-3.000$ e $500-4.400 \mu \mathrm{g} / \mathrm{kg}$ para os três anos de avaliação, respectivamente. Como esperado, os níveis médios por estados foram relativamente menores do que os valores individuais, sendo 840 (500 a 3.000), 1.580 (500 a 4.400) e 750 (600 a 1.800) $\mu \mathrm{g} / \mathrm{kg}$ no ano de 2012 (DPR\% de 51,0 / 84,7 / 27,05\%) para PR, RS e SC, respectivamente. Independente dos dados acima, se considerarmos o LMT recomendado pela FDA (1988) de $30.000 \mu \mathrm{g} / \mathrm{kg}$, todas amostras analisadas estavam dentro deste padrão.

Por outro lado, independente da origem da amostra ou período de avaliação, a ZON esteve presente em 97,7\% (1052) das amostras entre 2010 e 2012. A contaminação média foi de $308,7 \mu \mathrm{g} / \mathrm{kg}(\min 28,2 ; \max 1538) \mathrm{com}$ grande variabilidade entre os níveis (DP: 131,3 \& 211,1 e DPR\%: 42,1 \& $65,4 \%)$. Sendo os níveis médios encontrados semelhantes entre os estado da Região Sul de (a) 255,7 / 287,1 / 332,7; (b) 297,0 / 341,9 / 265,5 e (c) 344,3 / 334,6 / 302,8 $\mu \mathrm{g} / \mathrm{kg}$ para (a) PR, (b) RS e (c) SC nos anos de 2010, 2011 e 2012, respectivamente. Deste total, 75,5 \% (813) estava acima do LMT estabelecido no Uruguai $(200 \mu \mathrm{g} / \mathrm{kg}$ ) para milho e cevada, embora esse país não especifique limite para silagem (na qual o milho sofre processo de fermentação). O Brasil não tem limite estabelecido para ZON, independente do 
HORN, M.B. et al. Qualidade de silagens de milho para gado leiteiro produzidas na Região Sul do Brasil quanto às micotoxinas. PUBVET, Londrina, V. 8, N. 2, Ed. 251, Art. 1664, Janeiro, 2014.

tipo de alimento para o animal. Semelhante as FBs, os níveis individuais de contaminação por ZON variaram durante o período de estudo, na faixa entre 50,3 a $980,6 \mu \mathrm{g} / \mathrm{kg}$ e 82,2 a $1263 \mu \mathrm{g} / \mathrm{kg}$ (DPR\%: 55,4\% e 61,3\%, respectivamente) correspondendo aos estados de PR e SC no ano de 2010. Já no estado de RS os níveis foram na faixa de 28,2 a $850 \mu \mathrm{g} / \mathrm{kg}$ (DP/DPR\%: $153 / 51,5 \%)$ no mesmo ano. Importante enfatizar que as níveis mais elevadas ocorreram somente em três amostras isoladas do PR $(1065 \mu \mathrm{g} / \mathrm{kg})$ e SC (1263 e $1538 \mu \mathrm{g} / \mathrm{kg}$ ), diferente da maioria das amostras analisadas (Tabela 2). Possivelmente esta contaminação foi favorecida pela presença de Fusarium graminearum em maior quantidade e/ou alguma deficiência no processo de fermentação bem como, o teor elevado de umidade normalmente encontrado nesses produtos (64-82\%). Independente desses dados pontuais, os três estados apresentaram incidência de amostras contaminadas muitos semelhantes para ZON.

Quando esses dados são comparados com a literatura, foi observado que o percentual de amostras contaminadas por esta toxina foi superior ao reportado por Netto et al. (2002), os quais encontraram 39,1\% de contaminação por ZON, em 52 amostras de silagem de milho, avaliadas no período de 1997 a 2001. Diferente do presente estudo, que utilizou método imunoenzimático, os autores utiizaram cromatografia em camada delgada como metodologia analítica e não informaram seu LOQ. Ideal seria a utilização de métodos mais precisos e apurados como a cromatografia de alta eficiência com detectores de fluorescência e/ou massas. Embora a legislação brasileira não estabeleça limites de tolerância para a ZON, a maioria das silagens positivas no presente estudo estavam com níveis acima do LMT de outros países tais para milho como a França, incluindo o Uruguai (LMT: 50 e 200 $\mu \mathrm{g} / \mathrm{Kg})(\mathrm{FAO}, 2004)$.

Os fatores que podem ter propiciado essa contaminação podem ter sido a umidade da matéria-prima, a temperatura ambiente elevada em que as amostras foram submetidas durante o período de produção da silagem tanto do ambiente externo quanto interno do silo (SASSAHARA et al., 2003 e 
HORN, M.B. et al. Qualidade de silagens de milho para gado leiteiro produzidas na Região Sul do Brasil quanto às micotoxinas. PUBVET, Londrina, V. 8, N. 2, Ed. 251, Art. 1664, Janeiro, 2014.

CAVAGLIERI et al., 2005). Segundo Netto et al. (2002) climas muito umidos, com umidade relativa acima de $75 \%$ e temperaturas alternadas entre $22-27^{\circ} \mathrm{C}$ e $12-15^{\circ} \mathrm{C}$ podem propiciar o desenvolvimento de micotoxinas semelhante ao observadas nas amostras de silagem avaliadas na região sul do Brasil do presente estudo.

(a.2) Toxinas de armazenagem: são representadas principalmente pelas AFLs, as quais podem ser formadas durante a fermentação e/ou armazenagem das silagens, processos que ocorrem simultaneamente em silos tipo trincheira ou de superfície em áreas de criação de gado.

Das amostras de silagem de milho (1080) da região Sul do Brasil analisadas entre 2010 e 2012, estavam contaminadas nas faixas de 60,2 a $87,5 \% ; 53,9$ a $72,9 \%$ e 64,4 a $87,5 \%$ as provenientes dos estados do PR, RS e SC, respectivamente (Tabela 2). As médias de contaminação foram também semelhantes entre os estados, com ligeira elevação para os estados de RS e SC com 29,9 $(\min 5,0 ; \max 97,0)$ e $32,1(\min 5,0 ; \max 98,4) \mu \mathrm{g} / \mathrm{kg}$ para os anos 2012 e 2011 respectivamente. A formação dessas toxinas pode ter sido devido às técnicas inadequadas durante a colheita do milho em planta ou no seu armazenamento (BOUDRA et al., 2005; BRYDEN, 2012). Considerando que as AFLs são toxinas de armazenagem, as variações climáticas ocorridas no período de fermentação da silagem também podem ter favorecido sua formação já que tanto a formação quanto a armazenagem ocorrem simultaneamente. Na Figura 8 podemos observar as variações de temperatura (11 a $27^{\circ} \mathrm{C}$ ), de UR\% (55 a 93\%) e de chuvas acumuladas (5 a $340 \mathrm{~mm}$ ) no período de estudo. Outras características que podem contribuir para a contaminação são: (a) estruturas físicas inadequadas dos locais de armazenamento, (b) a presença de roedores e (c) condições anaeróbicas durante a produção da silagem (SASSAHARA et al., 2003; KALAC, 2011). O estado do PR foi o que apresentou níveis levemente menores de contaminação para AFLs com 23,2, 26,3 e 25,6 $\mathrm{\mu g} / \mathrm{kg}$ nos anos de 2010, 2011 e 2012, respectivamente. Foi observado também, tendência de aumento da 
HORN, M.B. et al. Qualidade de silagens de milho para gado leiteiro produzidas na Região Sul do Brasil quanto às micotoxinas. PUBVET, Londrina, V. 8, N. 2, Ed. 251, Art. 1664, Janeiro, 2014.

contaminação por AFLs de 2010 para 2012 (Figura 4b), assim como seus níveis (Figura 5), independente do estado da região Sul.

Em relação à legislação, contaminação para AFLs superiores a $50 \mu \mathrm{g} / \mathrm{kg}$ (LMT/Brasil em matérias primas e ingredientes destinados a alimentação animal - BRASIL, 1988) foram encontrados em 11,6\% (125) das amostras das silagens. Se avaliarmos por estado, foram encontrados 9,7\% (46 de 475) das amostras do PR, 11,3\% (31 de 275) do RS e 14,5\% (48 de 330) de SC. Se observarmos a distribuição destas amostras por ano avaliado, a porcentagem de amostras > LMT foi de 8,5\% (18 de 212) em 2010, 10,9\% (36 de 331) em 2011 e 13,2\% (71 de 537) em 2012.

(a.3) Faixas de contaminação: considerando que para algumas toxinas, o número de amostras contaminadas bem como, os níveis em relação ao número total de amostras, foram diversificados, a média calculada pode não refletir a realidade.

Portanto, através da distribuição dos níveis em faixas ( $<$ ou > aos LMT brasileiro / europeu / americano), foi possível ter uma imagem mais apurada da contaminação.

A Figura 4a apresenta a distribuição das amostras por faixas de concentração e sua relação com LMTs permitidos. Nela foi possível perceber que para as FBs, a maioria dos resultados (+) estava abaixo de $1.000 \mu \mathrm{g} / \mathrm{kg}$ (LMT Suiça: $1.000 \mu \mathrm{g} / \mathrm{kg}$ ). Já para ZON, a maioria dos resultados encontramse na faixa de $200-500 \mu \mathrm{g} / \mathrm{kg}(61,3$ a $68,5 \%)$ sendo que para o ano de 2011 , houve uma tendência a resultados mais altos nas faixas acima de $200 \mu \mathrm{g} / \mathrm{kg}$ (LMT Uruguai: $200 \mu \mathrm{g} / \mathrm{kg}$ para milho). Para as AFLs, a distribuição foi homogênea nas faixas de concentração. No entanto foi possível perceber tendência a resultados mais elevados em 2012 (com médias de 25,6, 29,9 e $27,3 \mu \mathrm{g} / \mathrm{kg}$ para o PR, RS e SC, respectivamente, todas abaixo do LMT do Brasil, porém, acima do estabelecido pelos EUA. Ainda pode ser observado que foi crescente entre os anos a porcentagem de amostras com níveis acima do LMT estabelecido pelo Brasil para AFLs (BRASIL,1988). 
HORN, M.B. et al. Qualidade de silagens de milho para gado leiteiro produzidas na Região Sul do Brasil quanto às micotoxinas. PUBVET, Londrina, V. 8, N. 2, Ed. 251, Art. 1664, Janeiro, 2014.

Tabela 2. Estatística da contaminação ${ }^{a}$ por micotoxinas em silagens da Região Sul do Brasil durante o período de 2010 a 2012

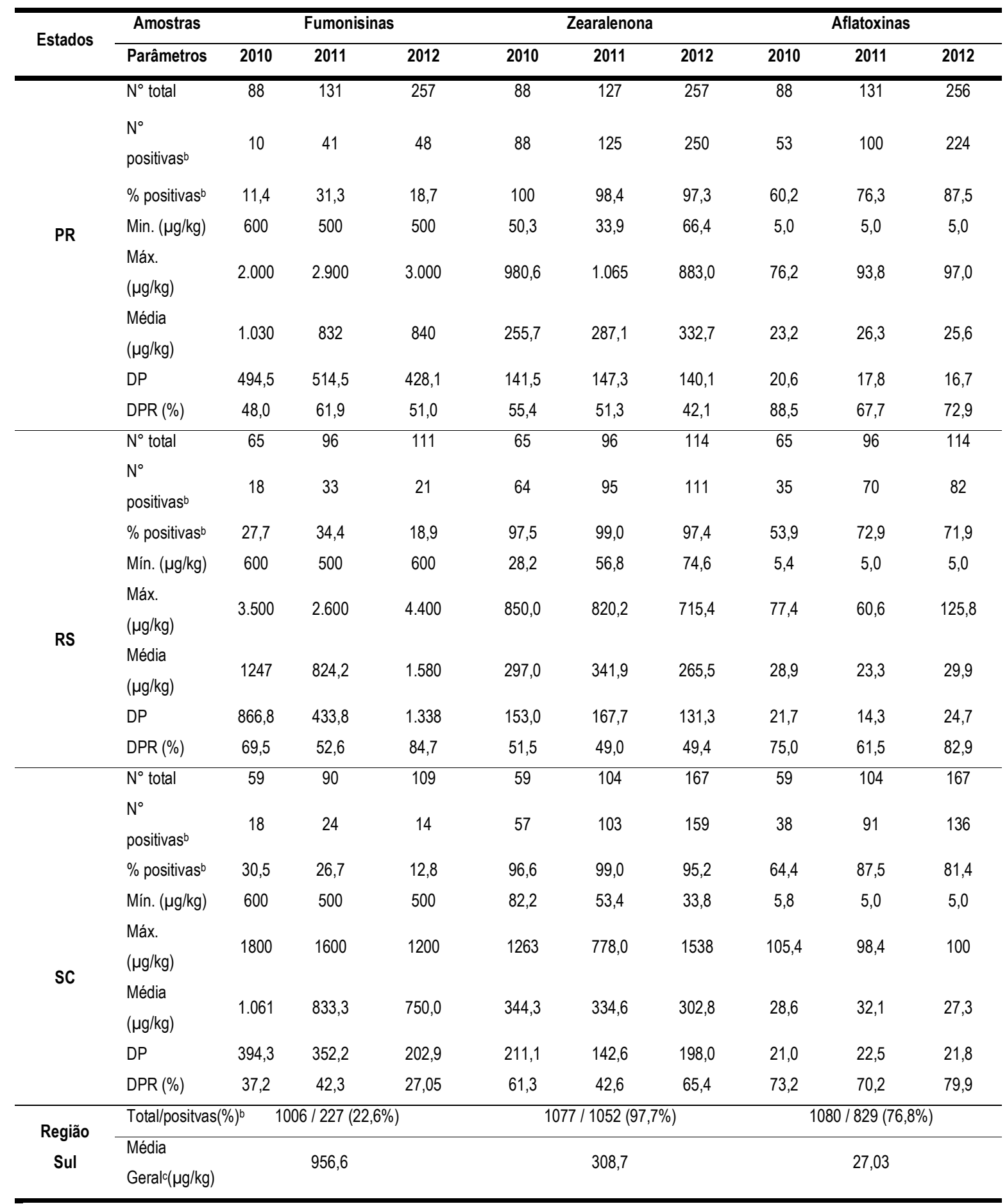

${ }^{a}$ concentração $\geq$ LOQ, DP - desvio padrão, DPR - desvio padrão relativo; ${ }^{b}>$ LOQ: 500/25/5 $\mu \mathrm{g} / \mathrm{kg}$ para FBs/ZON/AFLs, respectivamente; ${ }^{c}$ média considerando todas as amostras $\geq$ LOQ no período do estudo 
HORN, M.B. et al. Qualidade de silagens de milho para gado leiteiro produzidas na Região Sul do Brasil quanto às micotoxinas. PUBVET, Londrina, V. 8, N. 2, Ed. 251, Art. 1664, Janeiro, 2014.

\section{(a.4) Toxinas detectadas nas silagens versus recomendações: se} considerarmos os valores de referência oficiais estabelecidos pelo MAPA para AFLs em alimentos para animais, $11,6 \%$ (125) das amostras estava fora do limite estabelecido. Já se considerarmos a recomendação do FDA para FBs, nenhuma amostra apresentou valores fora do limite máximo e se considerarmos o LMT pela Suiça para milho $(1.000 \mu \mathrm{g} / \mathrm{kg}), 7 \%$ das amostras estavam com valores superiores ao estabelecido.

Por outro lado, se considerarmos a recomendação do CPFOR (UFPR, 2011), 93\% das amostras da região Sul do Brasil estavam dentro do limite aceitável para FBs, $51 \%$ para ZON e $61 \%$ para AFLs (Figura 6). Se avaliarmos as amostras de acordo com esta recomendação, nos 3 anos do estudo, foi possível perceber que vem ocorrendo diminuição no percentual de amostras críticas para FBs. Por outro lado, para as AFLs foi observado um aumento nas amostras apresentando níveis acima do limite crítico recomendado com 29, 44 e 40\% para os anos de 2010, 2011 e 2012, respectivamente (Figura 7). A maior ocorrência de amostras com concentração considerada crítica foi para ZON, com variação entre os estados de 52\% (246), 43,3\% (119) e de $47 \%$ (155) para o PR, RS e SC, respectivamente. Vale ressaltar, no entanto que esta informação está baseada em recomendações, e não em legislação específica. 


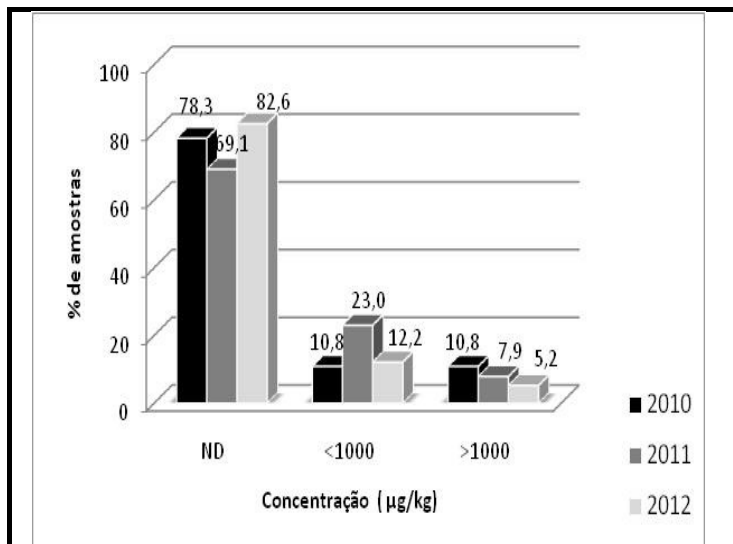

(a.1) FBs

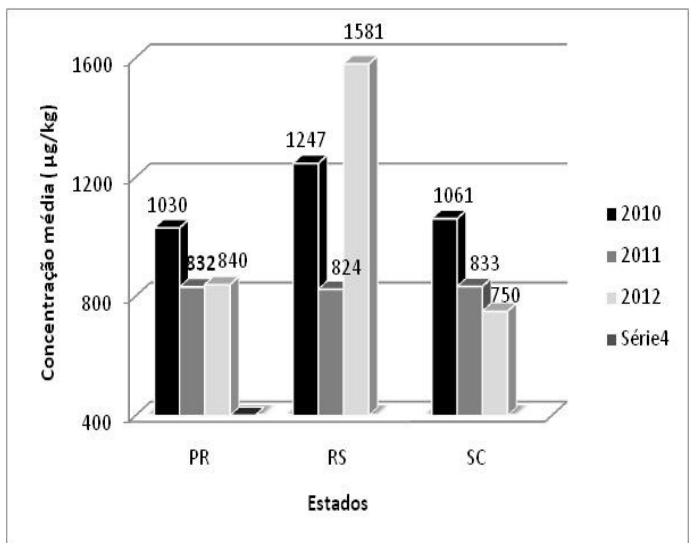

(b.1) FBs

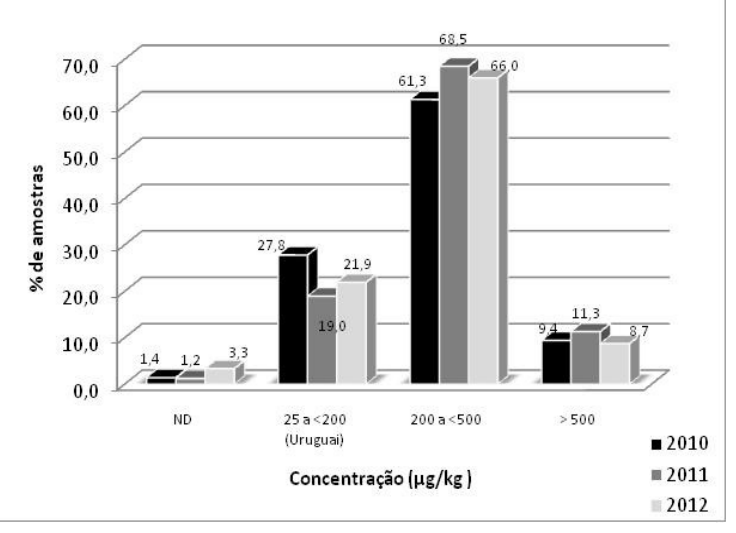

(a.2) ZON

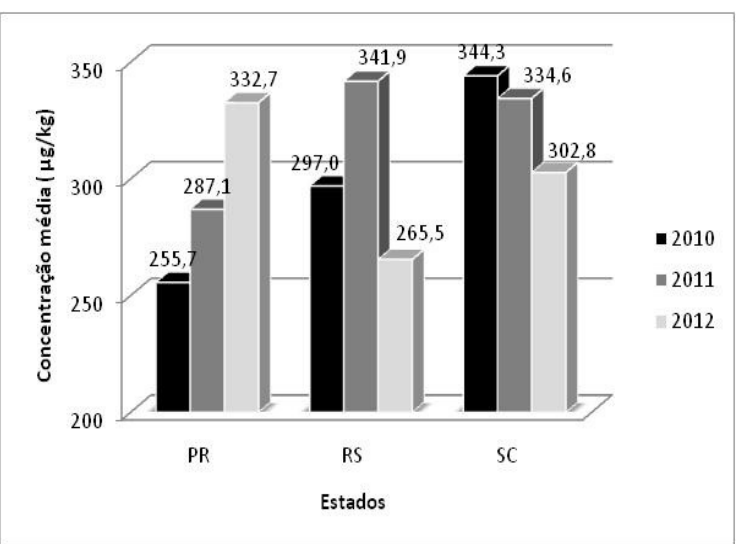

(b.2) ZON

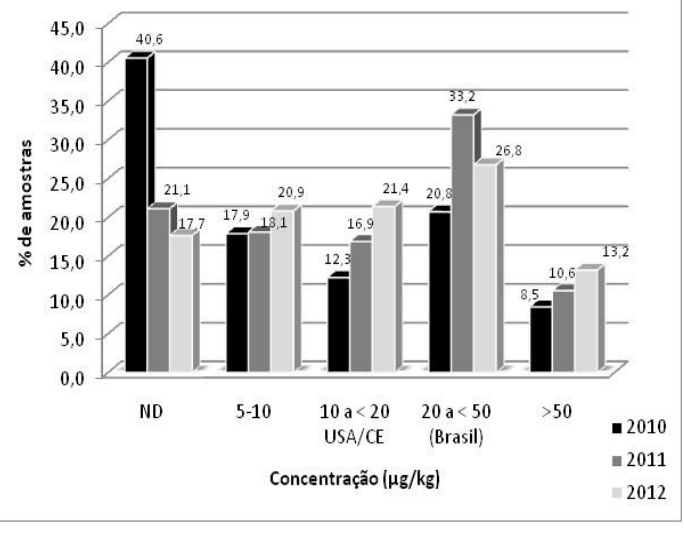

(a.3) AFLs

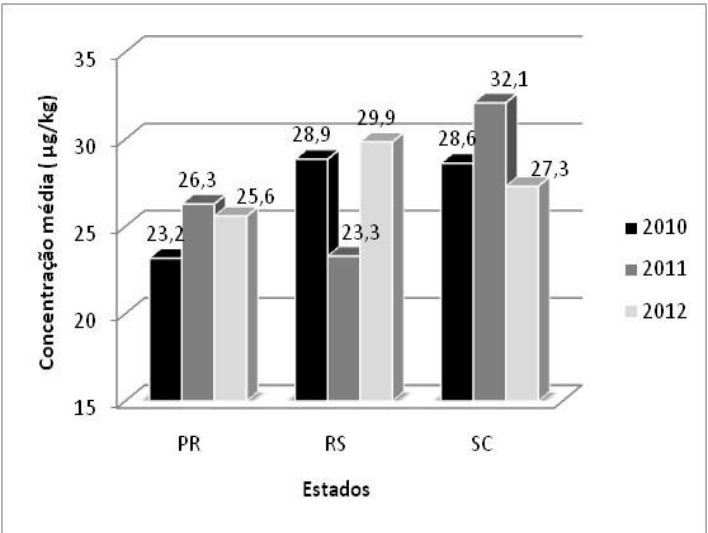

(b.3) AFLs

Figura 4. Contaminação por micotoxinas em silagens de milho da região Sul do Brasil: (a) porcentagem de amostras por faixas de concentração e (b) concentração média por estado e ano [(1) fumonisinas - FBs; (2) zearalenona - ZON e (3) aflatoxinas - AFLs]. LOQ do método: 500,25 e $5 \mu \mathrm{gg} / \mathrm{kg}$, para FBs, ZON e AFLs, respectivamente. LMT: 1 - Suiça $(1000 \mu \mathrm{g} / \mathrm{kg}), 2$-Uruguai $(200 \mu \mathrm{g} / \mathrm{kg}), 3$ - USA/CE $(20 \mu \mathrm{g} / \mathrm{kg})$ e Brasil $(50 \mu \mathrm{g} / \mathrm{kg})$ 


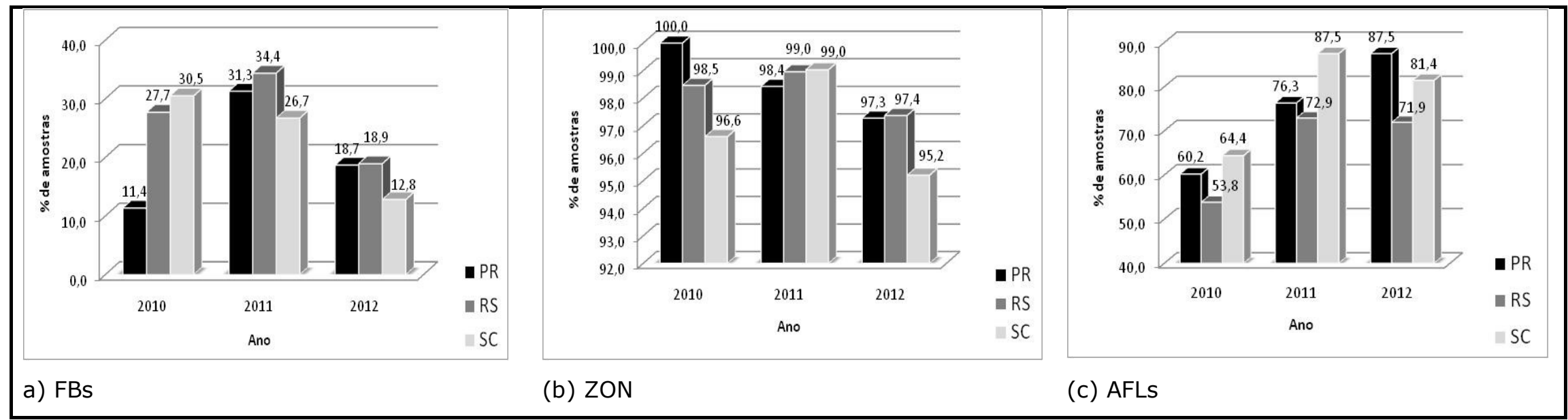

Figura 5. Incidência de amostras de silagem de milho contaminadas por (a) FBs, (b) ZON e (c) AFLs com concentração $\geq$ LOQ [ $500 / 25 / 5 \mu$ g/kg], respectivamente, coletadas de propriedades rurais dos estados do Paraná ( PR), Rio Grande do Sul (RS) e Santa Catarina (SC). 


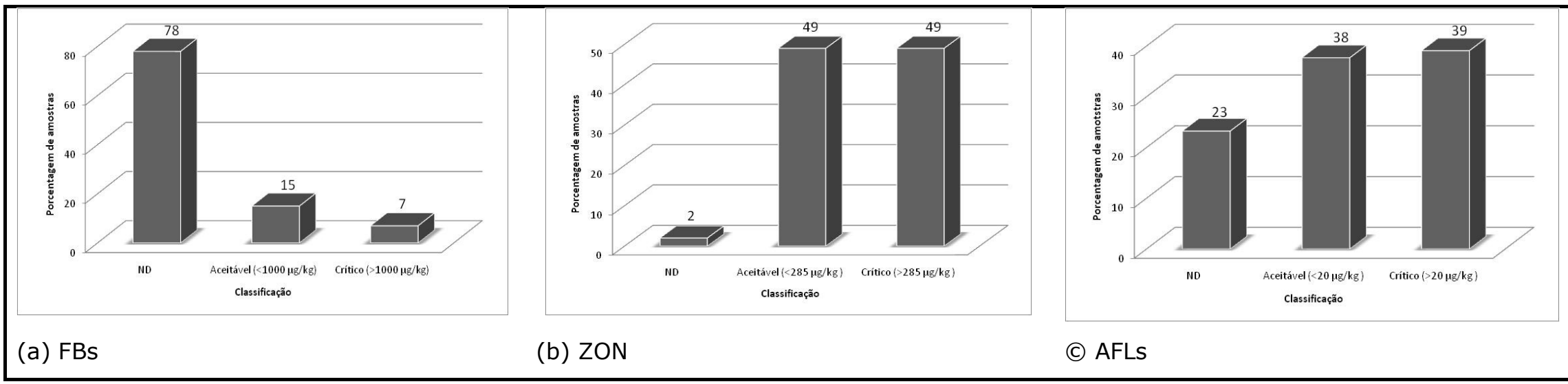

Figura 6. Classificação das contaminações de amostras de silagem de milho da região Sul do Brasil: (a) FBs, (b) ZON e (c) AFLs por ano de de acordo com as recomendações do CPFOR/UFPR. [Limite máximo crítico : > 20, $>286$ e $>1000 \mu \mathrm{g} / \mathrm{kg}$ e aceitável : $<19,<285$ e $<1000 \mu \mathrm{g} / \mathrm{kg}$ para as três toxinas, respectivamente. 
TOXINAS DE CAMPO

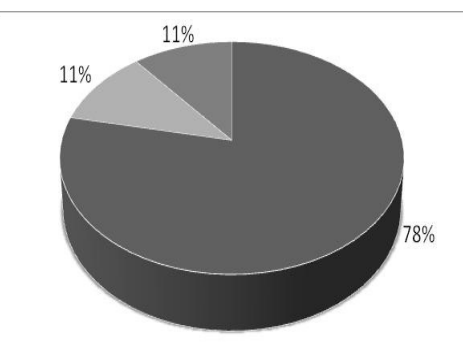

—ND «Aceitável $(<1000 \mu \mathrm{g} / \mathrm{kg})$ - Critico $(>1000 \mu \mathrm{g} / \mathrm{kg})$

FBs (a.1) 2010

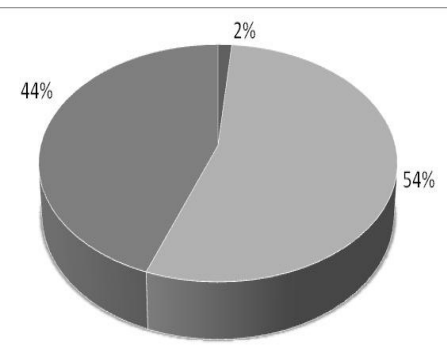

- ND $\backsim$ Aceitável $(<285 \mu \mathrm{g} / \mathrm{kg}) \quad$ - Crítico $(>285 \mu \mathrm{g} / \mathrm{kg})$

ZON (b.1) 2010

\section{TOXINAS PÓS-COLHEITA}

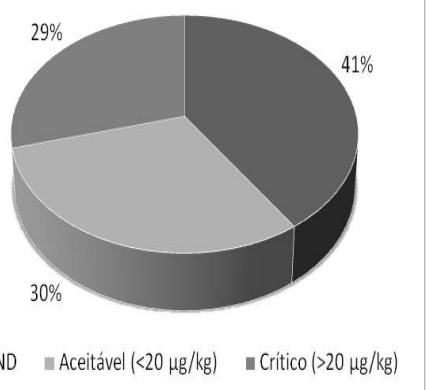

AFLs (c.1) 2010

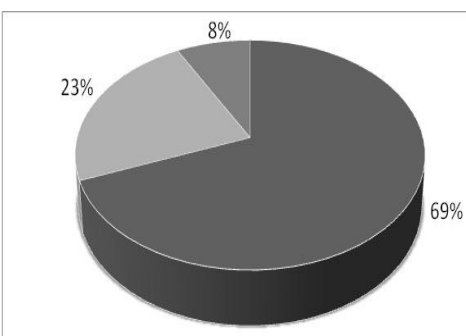

— ND Aceitável $(<1000 \mu \mathrm{g} / \mathrm{kg})$ - Crítico $(>1000 \mu \mathrm{g} / \mathrm{kg})$

(a.2) 2011

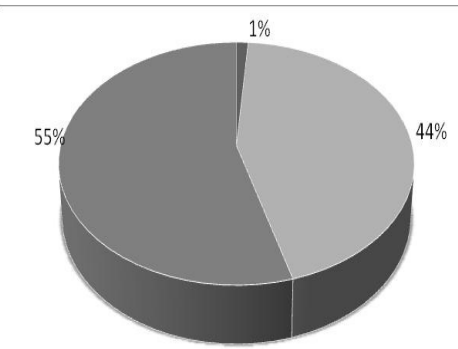

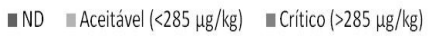

(b.2) 2011

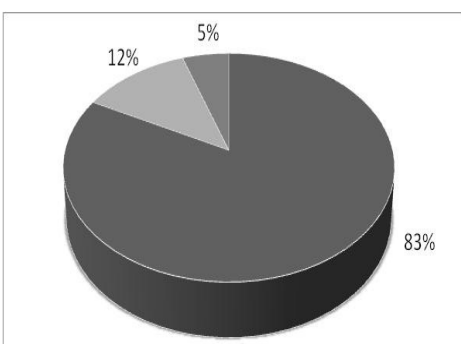

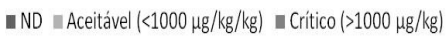

(a.3) 2012

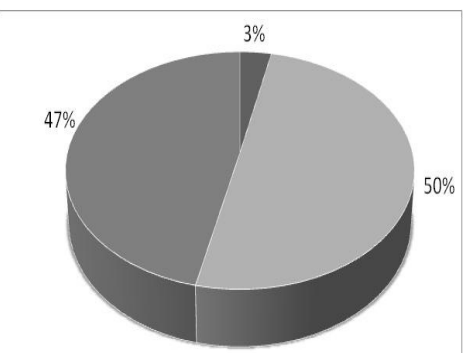

—ND $\backsim$ Aceitável $(<285 \mu \mathrm{g} / \mathrm{kg}) \quad$ - Crítico $(>285 \mu \mathrm{g} / \mathrm{kg})$

(b.3) 2012

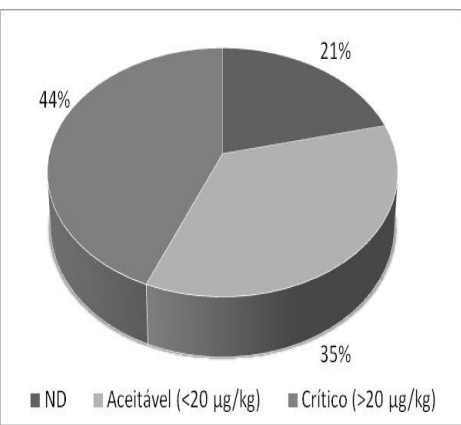

(c.2) 2011

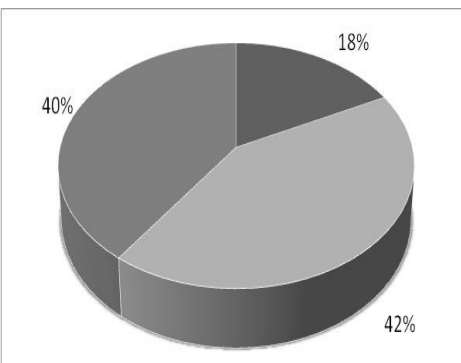

- ND -Aceitável $(<20 \mu \mathrm{g} / \mathrm{kg}) \quad$ - Crítico $(>20 \mu \mathrm{g} / \mathrm{kg})$

(c.3) 2012

Figura 7. Classificação das contaminações por (a) fumonisinas - FBs, (b) zearalenona - ZON e (c) aflatoxinas - AFLs por ano das amostras de silagem de milho da região Sul do Brasil de acordo com as recomendações do Centro de Pesquisa em Forragicultura da Universidade Federal do Paraná. [1:2010; 2:2011 e 3: 2012]. 
HORN, M.B. et al. Qualidade de silagens de milho para gado leiteiro produzidas na Região Sul do Brasil quanto às micotoxinas. PUBVET, Londrina, V. 8, N. 2, Ed. 251, Art. 1664, Janeiro, 2014.

\section{(b) Efeitos da Contaminação no Gado Leiteiro}

(b.1) Fumonisinas: de acordo com as recomendações do CPFOR (UFPR, 2011) são considerados níveis de contaminação aceitáveis, valores inferiores a $1.000 \mu \mathrm{g} / \mathrm{kg}$. A presença desta toxina na alimentação do gado leiteiro pode se tornar um problema para saúde pública, uma vez que ela pode ser transferida para o leite consumido pelo homem. Hammer et al (1996), citado por Spahr et al.(2000), estima uma transferência média de 0,05\%, após uma exposição oral de alimentação $3000 \mu \mathrm{g} / \mathrm{kg}$. Outro fator que deve ser abordado são os prejuizos econômicos decorrentes da presença dessas toxinas na alimentação do gado. Em um estudo publicado por Diaz et al. (2000) ocorreu uma menor produção de leite nos animais tratados com ração contaminada por 100.000 $\mu \mathrm{g} / \mathrm{kg}$ de FBs, no período de 70 dias. No entanto, nenhum traço de $\mathrm{FB}_{1}$ foi detectado no plasma de animais expostos a alimentação contaminada por 1000 ou $5000 \mu \mathrm{g} / \mathrm{kg}$ (PRELUSKY et al., 1995). Felizmente, no presente estudo, não houve identificação de amostras com valores tão elevados quanto os descritos/utilizados por Diaz et al. (2000). As médias encontradas foram relativamente baixas, assim como também a porcentagem de amostras contaminadas, de forma que podemos afirmar que, com excessão a algumas amostras, as FBs não foram um problema na silagem de milho avaliadas no período do presente estudo.

(b.2) Zearalenona: considerando os efeitos dessa toxina nos animais, os níveis médios encontrados no presente trabalho, foram inferiores ao descrito por Prelusky et al. (1990), o qual reporta que a ingestão pelo gado leiteiro de 50.000 a $165.000 \mu \mathrm{g} / \mathrm{kg}$ de ZON por um período de 21 dias, não foi suficiente para apresentar resíduos no leite. Outros estudos já realizados no Brasil e na Argentina também encontraram contaminações por ZON, em amostras de silagem de milho (SASSAHARA et al., 2003; CAVAGLIERI et al., 2005) a qual tem ação direta no sistema reprodutivo podendo ocasionar diminuição da fertilidade, diminuição das taxas de ovulação e produção do leite, vaginite e aumento uterino, mais especificamente em suínos (NONES \& SCUSSEL,2013). 
HORN, M.B. et al. Qualidade de silagens de milho para gado leiteiro produzidas na Região Sul do Brasil quanto às micotoxinas. PUBVET, Londrina, V. 8, N. 2, Ed. 251, Art. 1664, Janeiro, 2014.

(b.3) Aflatoxinas: já as AFLs, são classificadas como as toxinas de maior poder carcinogênico dentre as estudadas, afetando principalmente o fígado. As AFLs causam diminuição do rendimento do animal além de poder se biotransformar em $\mathrm{AFM}_{1}$ e passar a ser um perigo também para os seres humanos. Os dados obtidos em silagens no presente estudo foram maiores se comparados aos dados citados por Whitlow et al. (2005), onde foram encontrados $8 \%$ de amostras positivas das 461 amostras avaliadas na Carolina do Norte, EUA no período de 9 anos.

\section{(c) Característica da Região sul versus Micotoxinas}

Os três estados brasileiros pertencentes a Região Sul estão localizados abaixo do trópico de Capricórnio, na zona temperada com quatro estações bem definidas.

Uma característica bastante típica da região é apresentar variações de temperaturas durante as estações do ano, inclusive dentro da mesma estação. Podem chegar a temperaturas negativas no inverno $\left(\geq-4^{\circ} \mathrm{C}\right)$ a bastante elevadas no verão $\left(\leq 40^{\circ} \mathrm{C}\right)$ além de oscilações abruptas entre os dias e noites causando choque térmico e estresse fúngico, possibilitando a produção de toxinas, se os fungos presentes forem toxigênicos, principalmente para toxinas de campo. A região de coleta das amostras está situada nos planaltos dos estados do PR, RS e SC, e apesar da diferença ser pequena entre os estados (Figura 8 ), pode ser observado que a temperatura no estado do RS foi a que mais variou entre o período do estudo sendo que o ano de 2012 foi o mais quente entre os estados (média de $27^{\circ} \mathrm{C}$ no mês de fevereiro em SC).

A chuva acumulada $(\mathrm{mm})$ foi praticamente igual nos três estados, sendo que em 2010, houve um pequeno aumento em SC (340 mm no mês de abril). A UR\% foi maior para o estado do PR (Figura 8) com máxima de 93\% em maio de 2010.

A silagem de milho na região foi produzida nos meses de (a) dezembro e janeiro ( $\uparrow T^{\circ} \mathrm{C}$ e $\uparrow U R$ ) a partir do milho plantado entre agosto e setembro 
HORN, M.B. et al. Qualidade de silagens de milho para gado leiteiro produzidas na Região Sul do Brasil quanto às micotoxinas. PUBVET, Londrina, V. 8, N. 2, Ed. 251, Art. 1664, Janeiro, 2014.

( $\downarrow T^{\circ} \mathrm{C}$ e $\downarrow$ UR) e nos meses de (b) março e abril ( $\uparrow T^{\circ} \mathrm{C}$ ) do milho plantado em dezembro, portanto com condições de proliferação dos fungos com possibilidade de formação de toxinas.
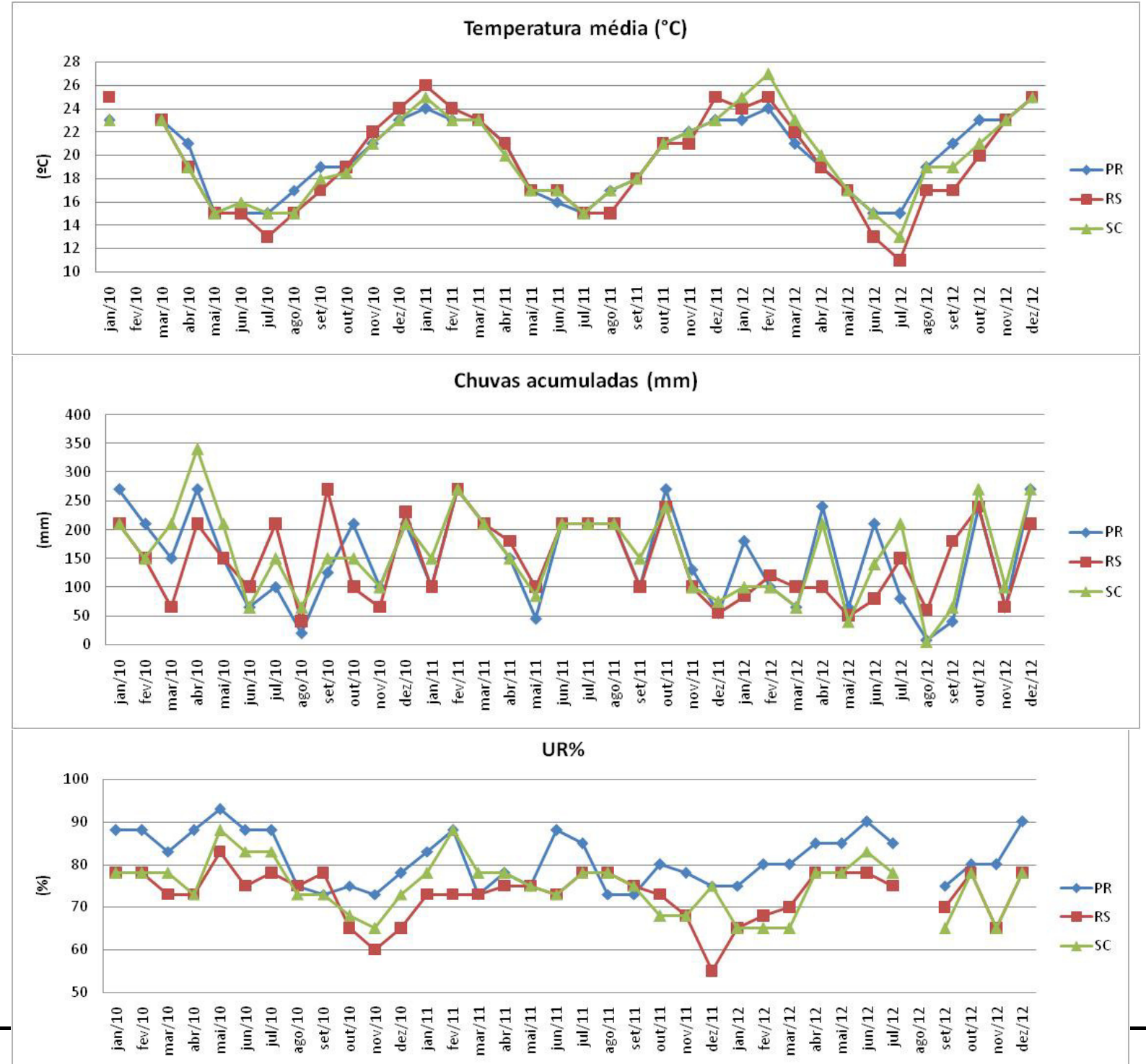

Figura 8. Condições climáticas: (a) temperatura $\left({ }^{\circ} \mathrm{C}\right)$; (b) índice pluviométrico (mm) e (c) umidade relativa - UR (\%) nos estados do Paraná (PR), Rio grande do Sul (RS) e Santa Catarina (SC) no período de 2010 a 2012 do presente estudo (dados compilados à partir do www.inmet.gov.br, 2013). 
HORN, M.B. et al. Qualidade de silagens de milho para gado leiteiro produzidas na Região Sul do Brasil quanto às micotoxinas. PUBVET, Londrina, V. 8, N. 2, Ed. 251, Art. 1664, Janeiro, 2014.

\section{CONCLUSÃO}

O principal problema da atividade fúngica em silagens é que, além da proliferação de fungos e outros microorganismos fermentadores, também podem se desenvolver os toxigênicos, com a possível produção de toxinas, levando a conseqüências graves para a performance animal.

Os dados obtidos demonstram que parte das silagens, fornecidas ao gado leiteiro nos três estados da Região Sul do Brasil, apresentava alguma contaminação pelas toxinas FBs / ZON / AFLs no período de estudo (2010 a 2012). Para FBs, quase a totalidade das amostras (93 \%) apresentou níveis abaixo do LMT (Suíça: $1000 \mu \mathrm{g} / \mathrm{kg}$ ), por outro lado, a ZON apresentou porcentagem $(75,5 \%)$, contudo para níveis acima de LMTs internacionais (Uruguai para milho: $200 \mu \mathrm{g} / \mathrm{kg}$ ). Já as AFLs, menos da metade das amostras (39\%) estava acima do LMT estabelecido pela Europa e Estados Unidos (CE\&EUA: $20 \mu \mathrm{g} / \mathrm{kg}$ ). Quando considerarmos somente o LMT brasileiro para AFLs (o único para micotoxinas em alimentos animal), 11,6\% de amostras estavam acima desse limite (Brasil: $50 \mu \mathrm{g} / \mathrm{kg} \%$ ).

Considerando que a produção de silagem de milho ocorre em condições favoráveis para o crescimento de fungos (teor de umidade $>63 \%$, umidade relativa de 55 a $93 \%$ e temperatura $>11^{\circ} \mathrm{C}$ ), o crescimento fungico é comum, principalmente em silagens mal vedadas e com baixa compactação. Portanto, há necessidade de adequação das práticas agricolas na produção da silagem (desde a colheita, durante a moagem, na compactação e período fermentativo) incluindo cuidados no tipo de silo utilizado (seu tamanho, característica de sua vedação e contato com o solo). Também é necessário um constante monitoramento dessas toxinas, a fim de evitar ou minimizar os eventuais danos econômicos e de produção. Além disso, a garantia na qualidade alimentar do gado leiteiro irá propiciar maior qualidade no leite, o qual é consumido pela população brasileira tanto in natura como através dos seus derivados. 


\section{REFERÊNCIAS BIBLIOGRÁFICAS}

BORUTOVA, R.; ARAGON, Y.A.; NÄHRER, K.; BERTHILLER, F. Co-occurrence and statistical correlations between mycotoxins in feedstuffs collected in the Asia-Oceania in 2010. Animal Feed Sci. Technol., v.178, n. 3-4, p.190-197, 2012.

BOUDRA, H.; MORGAVI, D.P. Micotoxinrisk evaluation in feeds contaminated by Aspergillus fumigatus. Animal Feed Science and Technology, v.120, n. 1-2, p.113-123, 2005.

BRASIL. Ministério da Agricultura Pecuária e Abastecimento. Portaria MA/SNAD/SFA no7 de 9 de Nov. de 1988. Diário Oficial da União, 9 nov. 1988. Sec. I, p. 21.968.

BRYDEN, W. L. Mycotoxincontamination of the feed supply chain: Implications for animal productivity and feed security. Animal Feed Science and Technology, v.173, n.1 2, p. 134158 2012.

CALONI, F.; SPOTTI, M.; AUERBACH, H.; OP DEN CAMP, H.; FINK-GREMMELS, J.; POMPA, G.In vitro metabolism of fumonisin $B_{1}$ by ruminalmicroflora. Vet. Res. Comm., v.24, p. 379-387, 2000.

CAVAGLIERI, L.R.; GONZALEZ PEREYRA, L.M.; PEREYRA, C.M.; MAGNOLI, C.E.; CHULZE, S.N. ; DALCERO, A.M. Fungal and mycotoxin contamination of cow feeding stuffs in Argentina. In: International Conference. Fifth Framework Program.European Union Myco-Globe Project. European commission, 13-16 September, Accra, Ghana, 2005.

D'MELLO, J.P.F.; PLACINTA, C.M.; MACDONALD,A.M.C. Fusarium mycotoxins: a review of global implications for animal health, welfare and productivity. Animal Feed Sci. Technol. , v.80, n. 3-4, p.183-205,1999.

DIAZ, D.E.; HOPKINS, B.A.; LEONARD, L.M.; HAGLER, W.M.; WHITLOW, L.W. Effect of fumonisin on lactating dairy cattle. J. Dairy Sci., v.83, p. 1171, 2000.

DRIEHUIS, F.; SPANJER, M.C.; SCHOLTEN, J.M.; GIFFEL, M.C.T. Occurrence of mycotoxins in feedstuffs of dairy cows and estimation of total dietary intakes. J. Dairy Sci., v.91, p. 42614271, 2008.

DUARTE, S.C.; ALMEIDA, A.M.; TEIXEIRA, A.S. ; PEREIR, A.L.; FALCÃO, A.C.; PENA, A.; LINO, C.M. Aflatoxin M1 in marketed milk in Portugal: Assessment of human and animal exposure. Food Contr., v. 30, 411-417, 2013.

EFSA (The European Food Safety Authority).Opinion of the scientific panel on contaminants in food chain on a request from the commission related to fumonisins as undesirable substances in animal feed. EFSA J., 235 (2005), pp. 1-32.

EUROPEAN COMMUNITY.Directive 2002/32/EC of the European Parliament and of the Council of 7 May 2002 on undesirable substances in animal feed.

FDA, U.S. Food and Drugs Administration - disponível em www.fda.gov / Animal Veterinary /Products/AnimalFoodFeeds/Contaminants. Reunião de 09 de novembro de 1988 - Seção I, página 21.968, 1988: acessado em 27 fevereiro 2013.

FAO, Food Agriculture Organization. Worldwide regulationsfor mycotoxins in food and feed in 2003 - V.81, 173p, Roma, 2004. 
HORN, M. B.; BORDIGNON, J.; ASSUNÇÃO, M.; LUCHTENBERG, R.; SCUSSEL, V. M.. Levels of Contamination by Mycotoxins in Corn Silages for Ruminants in Southern Brazil: 2010 to 2011. In: Mycored, 2011, Mendoza. Strategies to reduce the impact of mycotoxins in Latin-America in a global context., 2011.

INMET. Instituto Nacional de Metereologia.Disponível em: www.inmet.gov.br. Acessado em 20 de fevereiro de 2013.

KALAČ,P. The effects of silage feeding on some sensory and health attributes of cow's milk: A review. Food Chem., v.125, n.2, p.307-317, 2011.

KELLER,L.A.M.; GONZÁLEZ PEREYRA,M.L.; KELLER, K.M.; ALONSO,V.A.; OLIVEIRA,A.A.; ALMEIDA,T.X.; BARBOSA,T.S.; NUNES,L.M.T.; CAVAGLIERI,L.R.; ROSA,C.A.R. Fungal and mycotoxins contamination in corn silage: Monitoring risk before and after fermentation. $J$. Stored Products Res., v.52, p. 42-47, 2013.

MATHUR, S.; CONSTABLE, P.D.; EPPLEY, R.M.; WAGGONER, A.L.; TUMBLESON, M.E.; HASCHEK, W.M. Fumonisin $B_{1}$ is hepatotoxic and nephrotoxic in milk-fed calves. Toxicol. Sci., v.60, p. 385-396, 2001.

MERCOSUL. Regulamento técnico MERCOSUR sobre límites máximos de aflatoxinas admisibles en leche, maní y maíz. GMC/RES. N 25/02.

NEOGEN. Procedimento para análise de Fumonisina/Veratox - disponível em http://www.neogen.com/FoodSafety/pdf/procedures. Acessado em 27 fevereiro de 2013.

NEOGEN.b - Procedimento para análise de Zearalenona/ Veratox - disponível em ttp://www.neogen.com/FoodSafety/pdf/procedures. Acessado em 27 fevereiro de 2013.

NEOGEN.c - Procedimento para análise de Aflatoxina / Veratox - disponível em http://www.neogen.com/FoodSafety/pdf/procedures. Acessado em 27 fevereiro de 2013.

NETTO, D.P.; ZANLUCHI, A.T.; SASSAHARA, M.; YANAKA, E. K. Micotoxins in animal feed detected from May/1997 to March/2001 at the Veterinary Toxicology Laboratory of State University of Londrina. Londrina - Paraná State. Semina: Ciências Agrárias, v. 23, n. 1, p. 6369, 2002.

NONES J.; SCUSSEL, V.M. Zearalenone and its metabolites: Effect on Swine Reproductive Performance. Pubvet in press, 2013.

PRELUSKY, D.B.; SCOTT, P.M.; TRENHOLM, H.L.; LAWRENCE, G.A. Minimal transmission of zearalenone to milk of dairy cows. J. Environ. Sci. Health (B), 25:87-103, 1990.

PRELUSKY, D.B.; SAVARD, M.E.; TRENHOLM, H.L. Pilot study on the plasma pharmacokinetics of fumonisin $B_{1}$ cows following a single dose by oral gavage or intravenous administration. Nat. Toxins, v.3,p. 389-394, 1995.

QUEIROZ,O.C.M.; HAN,J.H.; STAPLES,C.R.; ADESOGAN, A.T. Effect of adding a mycotoxinsequestering agent on milk aflatoxin $M_{1}$ concentration and the performance and immune response of dairy cattle fed an aflatoxin $B_{1}$-contaminated diet. J. Dairy Sc., v.95, n.10, p.5901-5908, 2012.

RUANGWISES, N.; RUANGWISES, S. Aflatoxin $M_{1}$ contamination in raw milk within the central region of Thailand. Bull. Environ. Cont. Toxicol., v.85,n.2, p,195-198, 2010. 
SASSAHARA, M.; YANAKA, E. K.; PONTES, D. Occurrence of aflatoxins and zearalenone in feedstuffs destined to dairy cattle consumption in Northern Parana, Brazil.Semina: Ciências Agrárias, v. 24, n. 1, p. 63-72, 2003.

SCAFF, R. M. C.; SCUSSEL V. M., corn Fumonisins $B_{1}$ and $B_{2}$ in corn-based products commercialized in the state of Santa Catarina - Southern Brasil. Food Sci. Technol., 2004.

SCUSSEL, V. M. - Micotoxinas em Alimentos - Florianópolis, Editora Insular, 144p, 1998.

SCUSSEL, V. M. Aflatoxin and Food Safety: Recent South American Perspectives. J. Toxicol. v.23, n. 2 e 3, p. 179-216, 2004.

SILVA, J. S. Análise de Alimentos (métodos químicos e biológicos), $2^{a}$ edição, Viçosa: UFV, 1998.

SIMGE, Sistema de Meteorologia e Recursos Hídricos de Minas Gerais. Base de Dados Meteorológicos e Hidrológicos (2011) Acesso em 03.11 .13 www.simge.mg.gov.br/base_dados/index.html

SMITH, J.F., DIMENNA, M.E., McGOWAN, L.T. Reproductive performance of coopworth ewew following oral doses of zearalenone before and after mating. J. Reprod. Fertil., 89:99-104, 1990.

SPAHR,U.; WALTHER, B.; SIEBER, R.; GAFNER, J.L.; GUIDON, D.S. Carry over of mycotoxins into milk: a review. Agrarforschung, v.7, p. 68-73, 2000.

SPOTTI, M.; POMPA, G.; CALONI, F. Fumonisin $B_{1}$ metabolism by bovine liver microsomes. Vet. Res. Comm., v.25, p. 511-516, 2001.

TONON K. M.; REITER M. G. R. ; SCUSSEL V. M. Mycotoxins Level in Human Milk: a Menace to Infants and Children Health. Current Nutr. \& Food Sci., v.9, p. 1-10, 2013

UFPR, Universidade Federal do Paraná (UFPR). CPFOR - Centro de Pesquisa em Forragicultura. Disponível em: http://www.ensilagem.com.br> Acesso em: 05 out. 2011.

WEAVER, G. A.; KURTZ, H. J.; BEHRENS, J. C.; ROBINSON, T. S.; SEGUIN, B.E.; BATES, F.Y.; MIROCHA, C.J. Effect of zearalenone on the fertility of virgins dairy heifers. American J. Vet. Res., Chicago, v.47, n. 6, p.1395-1397, 1986.

WHITLOW L.W., HAGLER, W.M. Mycotoxins: A Review of Dairy Concerns. Mid-South Ruminant Nutr. Conf., EUA, 2005. 